\title{
Aceleração e Transformações: Marcas da Tecnologia Digital para Além da Imagem Cinematográfica ${ }^{1}$
}

\author{
Liana Gross Furini \\ Mestranda do PPGCOM da Famecos/ \\ PUCRS, mesma universidade em que se \\ formou em Publicidade e Propaganda. \\ Sua pesquisa é na área de pirataria e \\ divulgação online.
}

\section{Roberto Tietzmann}

Professor do programa de pósgraduação em comunicação social da PUCRS e orientador das pesquisas. Pesquisa interfaces entre efeitos visuais, montagem, design e narrativa cinematográfica.

\section{Vanessa Valiati \\ Mestranda do programa de pós- graduação em comunicação social da PUCRS e especialista em Economia da Cultura, pela UFRGS. Pesquisa financiamento coletivo de obras audiovisuais.}

\section{${ }^{1}$ Trabalho apresentado no GP Cinema do XIII Encontro dos Grupos de Pesquisa em Comunicação, evento componente do XXXVI Congresso Brasileiro de Ciências da Comunicação.}

\footnotetext{
2 Podemos situar o primeiro movimento do cinema relacionado a características industriais o fato de tanto os irmãos Lumière serem herdeiros de uma próspera empresa de material fotográfico, como pontua Mannoni (2003), quanto Edison ser um multifacetado inventor e empresário norte-americano com mais de duas décadas de inventos incluindo melhorias no telégrafo e o fonógrafo, conforme Musser (1994).
}

Resumo: Neste artigo, problematizamos a presença de marcas de mudanças no fazer e consumir cinematográfico proporcionadas pela digitalidade. Discutiremos estas marcas a partir de três pontos da realização cinematográfica: o levantamento de recursos com ênfase no financiamento coletivo de obras por crowdfunding que favorece obras à margem dos padrões comerciais; as transformações da digitalidade em imagens na captação e na pós-produção que flexibilizam a mescla de imagens; e a circulação de obras por meios oficiais e extraoficiais que dinamizam o consumo.

Palavras-chave: cinema; tecnologias digitais; internet; crowdfunding.

Abstract: In this article, we question the presence of indexes of changes in film making and consumption provided by digital technologies. We will discuss these indexes from three points of film production: fundraising with emphasis on collective financing of contents by crowdfunding that favors movies on the fringe of mainstream patterns; transformations provoked by digitality in images in capture and post-production that facilitate the blending and manipulation of images, and the circulation official and unofficial means that accelerate consumption.

Keywords: cinema; digital technologies; internet; crowdfunding.

\section{Introdução}

Tradicionalmente o cinema se afirmou como um meio que negociou contradições; entre seus aspectos industriais ${ }^{2}$ e aspirações artísticas; entre o uso da tela como janela para um cotidiano ou como a expressão do surreal e do fantástico; a mímese da natureza e a síntese da fantasia. Situada entre todas estas fronteiras residia a película fotossensível, principal diferencial tecnológico da captação, edição e distribuição de imagens em movimento nas primeiras décadas do meio. A ideia que a arte e o negócio do cinema seriam vinculados exclusivamente a este suporte entra em crise a partir da consolidação da televisão na década de 1950 e chega a um ponto crítico com a percepção da crescente digitalização das imagens, meios e suas ferramentas pelas plateias, críticos e acadêmicos nos últimos vinte anos.

Segundo Negroponte (1995) o conceito sumário de digitalização é a tradução de átomos para bits, ou seja, o deslocamento de registros feitos em um suporte material para espaços imateriais de informação. Santaella (2007: 301) define bit como "o menor elemento atômico no DNA da informação", uma dupla metáfora que recupera a noção de que há um conceito indivisível (análogo ao átomo) e estruturante (como o DNA). Como consequência da desmaterialização dos suportes de informação é facilitada a manipulação dos conteúdos assim registrados, uma 
${ }^{3}$ As primeiras imagens digitais foram amplamente difundidas a partir de meados da década de 1960, vinculadas à transmissão de dados de sondas espaciais conforme de acordo com Gaskell (2003), ferramentas para fazer o replay de trechos de eventos esportivos conforme Owens (2007).

${ }^{4}$ A partir de meados da década de 1960 já surgiram diversas animações experimentais de caráter não figurativo como pontua Youngblood (1970).

${ }^{5} \mathrm{~A}$ história do cinema enquanto negócio sempre dependeu de apostas em filmes que resultassem em risco financeiro e retorno espetacular é traçada por Block \& Wilson (2010) e se estende dos primeiros dias aos meados do século XXI.

${ }^{6}$ Entendemos produção como a atividade de planejamento e gestão do filme e seus diversos recursos. ideia amparada por Lessig (2008) e Santaella (2007), entre outros. Usamos neste texto o termo "digitalidade" para denominar de maneira ampla as modificações provocadas pelo uso destas tecnologias no cotidiano de realização e análise de cinema.

Embora a entrada de tecnologias digitais nas imagens em movimento tenha se originado às margens ${ }^{3}$ do circuito de produção e de exibição do cinema, elas são percebidas em filmes de longa-metragem ${ }^{4}$ a partir do princípio da década de 1970 como suporte a efeitos visuais, primeiro em títulos de ficção científica como Westworld - Onde Ninguém tem Alma (Crichton, 1973) e Guerra Nas Estrelas (Lucas, 1977). Desde o princípio, portanto, a digitalidade nas telas é percebida a partir de um binômio que sugere, de um lado, a presença de ferramentas distintas das convencionais e, de outro, mudanças sensíveis naquilo que a imagem oferece ao espectador.

Embora o alinhamento entre capital, tecnologia e espetáculo continue vigente no cinema de grande orçamento contemporâneo ${ }^{5}$, neste artigo questionamos a presença mais ampla de transformações proporcionadas pela digitalidade no fazer e no consumir cinematográfico em um panorama tensionado e potencializado pelas redes sociais em meios digitais. Entendemos aqui que conceitos como a inteligência coletiva de Lévy (1998) e o caráter massivo sublinhado por Surowiecki (2006), Jenkins (2009) e Braet e Spek (2010) apontam para a descentralização e a dissociação das estruturas tradicionais de realização de obras cinematográficas de forma complementar às práticas já existentes.

Discutiremos as marcas desta digitalidade de maneira não exaustiva a partir de três ângulos situados em diferentes momentos da realização cinematográfica: o levantamento de recursos para um filme com ênfase no financiamento coletivo de obras por crowdfunding; as transformações da digitalidade em imagens na captação e na pós-produção; e a circulação de obras por meios oficiais e extraoficiais, costumeiramente rotulados de pirataria. Como objeto, escolhemos obras realizadas na última década, em que estas práticas inovadoras dialogam com os espaços tradicionais evidenciando tanto a ruptura quanto a continuidade.

\section{Crowdfunding: financiamento coletivo e descentralização da produção}

No que diz respeito ao financiamento, a consolidação da digitalidade trouxe complementações significativas para a produção cinematográfica ${ }^{6}$. Braet e Spek (2010) apontam quatro principais características da cadeia produtiva do cinema tradicional que são desconstruídas com a inovação trazida pelas redes digitais: custo elevado, que evita a participação dos não-profissionais; conteúdo entregue de forma cronológica, ao lado de uma cadeia de distribuição vertical; o consumo em pontos específicos (TV, cinema, DVD); e o conteúdo vendido em pacotes únicos (não se pode optar por diferentes filmes simultaneamente).

Ao invés da dependência de uma estrutura rígida, vinculada a produtoras estabelecidas, cujo financiamento era proveniente de grandes patrocinadores e de leis de incentivo, é possível detectar um movimento em prol da produção independente com a participação da audiência. O fato, por si só, não configura um fenômeno inédito - sempre houve cineastas à margem das grandes produções e orçamentos - mas sim, novos modos de produção facilitados pela inclusão tecnológica e pelo crescimento das redes conectadas.

O financiamento coletivo, ou crowdfunding, está inserido neste contexto de ruptura e transformação e tem sido uma alternativa viável para o financiamento de produtos culturais. Filmes, séries, videoclipes, shows e uma variada lista de produtos são financiados com o apoio da multidão. Na prática, o sistema funciona da seguinte maneira: o realizador define o projeto, estipula o valor, as contrapartidas (recompensas aos doadores), o prazo limite, cadastra em um 
${ }^{7}$ A relação dos filmes disponível em: <http://www.kickstarter.com/blog/ kickstarter-at-sundance-2010-14-filmsand-counting>. Acesso em 10 out. 2012. ${ }^{8} \mathrm{O}$ curta-metragem está disponível em: $<$ http://inocentedoc.com>. Acesso em 26 mai. 2013.

${ }^{9}$ Disponível em <www.catarse.me>. Acesso em 1 abr. 2012.

${ }^{10}$ Disponível em < http://catarse.me/pt/ projects/459-belo-monte-anuncio-deuma-guerra>. Acesso em 17 ago. 2012.

${ }^{11}$ Disponível em < http://catarse.me/pt/ dominiopublico\#about>. Acesso em 02 dez. 2012. site específico e fica responsável pela divulgação entre a sua rede de possíveis colaboradores. Caso o valor não seja atingido no prazo estipulado, o projeto não é financiado e o dinheiro retorna aos colaboradores. Se atingir ou ultrapassar a meta, o inheiro é repassado e o projeto realizado. Os sites mantêm-se com a cobrança de uma porcentagem sobre o valor total do projeto.

O modelo consolidou-se a partir de 2009, quando a plataforma Kickstarter foi lançada nos Estados Unidos. Atualmente, a plataforma tornou-se a referência mundial no assunto e já movimentou mais de US\$600 milhões. Na área audiovisual, ajudou a captar recursos para 14 filmes $^{7}$ que foram exibidos no Sundance Festival. Recentemente, o curta-metragem Inocente, financiado por meio do site foi ganhador do Oscar na categoria documentário de curta-metragem ${ }^{8}$.

O projeto do Kickstarter que obteve a maior arrecadação (mais de US\$ 5 milhões) foi Veronica Mars Movie Project, filme baseado em uma série americana cancelada depois de três temporadas e que deixou muitos fãs à espera de um final. Depois do sucesso alcançado via crowdfunding, a Warner Bros resolveu apoiar o projeto, garantindo sua execução. Outro filme que consta dentre os maiores arrecadadores (US\$ 3 milhões) é o Wish I was here, em que o ator Zach Braff estreia como diretor.

Roteiros inusitados, que não encontrariam espaço nas majors também se beneficiam com o modelo. Como é o caso do filme Iron Sky, coprodução finlandesa, australiana e alemã, dirigida por Timo Vuorensola, uma ficção científica sobre nazistas escondidos no lado oculto da lua que buscam vingança décadas após o final da Segunda Guerra Mundial. A fiç̧ão científica destaca-se por aliar o uso do crowdfunding em várias plataformas a outras formas de financiamento, como fundos de apoio tradicionais, investidores privados (crowd invest) e merchandising de produtos vinculados ao filme, arrecadando mais de $€ 6$ milhões.

Inspirado na iniciativa do americano Kickstarter, a plataforma brasileira Catarse ${ }^{9}$ também tem impulsionado o financiamento de filmes, em sua maioria de baixo orçamento. Em 2011, o documentário Belo Monte - Anúncio de uma Guerra ${ }^{10}$, do diretor Andre D'Elia, sobre a construção da usina hidrelétrica de Belo Monte, gerou mais de $R \$ 140$ mil em dois meses, revertidos para a sua finalização. Outra iniciativa que podemos inserir no mesmo contexto é o projeto Domínio Público ${ }^{11}$. O filme está sendo realizado há cerca de um ano e pretende investigar para onde está indo o dinheiro investido para a Copa do Mundo e Olimpíadas do Rio de Janeiro, além de mostrar, como uma das consequências da corrupção, a remoção dos moradores de favelas pacificadas, agora consideradas áreas de interesse imobiliário, para zonas afastadas e sob domínio de milícias. O documentário baseia-se também em depoimentos dos deputados Marcelo Freixo e Romário. 0 valor solicitado por meio de crowdfunding foi de mais $\mathrm{R} \$ 90$ mil e o arrecadado atingiu mais de $\mathrm{R} \$ 106 \mathrm{mil}$.

Pode-se perceber que os processos abordados até aqui valem-se de mecanismos coletivos amparados por uma rede de colaboração que, de acordo com Benkler (2006), é fundamentada na produção da informação (finanças, softwares, ciência), cultura (filmes, música) e manipulação de símbolos (publicidade, marcas), e permite uma maior participação do consumidor.

No entanto, Felinto (2012) ressalta os problemas estruturais que afligem as plataformas de financiamento colaborativo, como a falta de transparência ou os percentuais cobrados pelo serviço a cada doação, mas lembra que isso não invalida a aplicação de uma lógica do compartilhamento para as ideias que não têm apoio do grande capital. "De todo modo, o crowdfunding corresponde àquilo que parece ser um legítimo anseio de um público que já não parece se contentar com o simples consumo de produtos midiáticos sobre os quais ele não possui nenhuma ingerência" (FELINTO, 2012: 137). 
Sorensen (2012) conclui, em estudo comparativo entre os documentários financiados pela televisão pública no Reino Unido e os financiados por meio do crowdfunding, que apesar das inovações, a mídia tradicional ainda tem grande influência sobre os projetos realizados. O nome, marcas de referência, a distribuição nos canais de TV e festivais ainda determinam o que vai ser produzido. É o que se pode perceber nos casos de maior arrecadação de valor supracitados. A série, o filme dirigido por um autor conhecido ou ainda, no caso brasileiro, o contexto no qual as campanhas são lançadas têm grande influência sobre a decisão dos doadores, ou seja "o capital cultural de produtores e usuários também contribui para a manutenção de velhas hegemonias e hierarquias de gosto" (SORENSEN, 2012: 730).

Portanto, como explicam Braet e Spek (2010), é importante considerar a relação do contexto geral e as características de cada filme em particular. A internet alterou a cadeia produtiva do cinema, que antes era linear e agora é modular, de modo que o conteúdo passa a ser consumido em dispositivos variados, sem o controle dos proprietários e distribuidores. Os autores ressaltam que ainda assim, no caso dos cineastas independentes, que empregam inúmeras estratégias combinadas para obter os recursos necessários, a atenção dispensada pelos críticos e a participação em festivais ainda são imprescindíveis para o sucesso. No caso do crowdfunding especificamente, Braet e Spek (2010) apontam para o seu uso no cinema como forma de financiamento secundário, um critério para medir a popularidade do projeto em seleções de projetos para prêmios ou incentivos culturais.

\section{Digitalidade na superfície da imagem: as sínteses e o transbordamento do cotidiano}

Abordar a presença da digitalidade na superfície de imagens audiovisuais é algo complexo, dada a variedade de ocasiões em que esta relação se estabelece. Aqui destacamos três linhas para a discussão, relacionadas à captação, à pós-produção e à participação em massa de produtores contemporâneos. É constante a ideia de substituição de ferramentas e processos ao longo de todas as instâncias, uma marca trazida ao cinema por sua base industrial e tecnológica no qual uma parte do processo - as máquinas - pode ser modificada por necessidade ou por desejo; no entanto, o fator humano, aqui relacionado com a expressividade criativa e a ambição artística, não opera da mesma maneira.

É possível falar de tecnologias digitais no cinema primeiro considerando um conceito simples: estariam em lugar de ferramentas e rotinas de trabalho já existentes. Nesta linha, situa-se o digital como uma tecnologia de registro da imagem que substitui alguma convenção técnica pregressa. A discussão desta linha corre o risco de permanecer no óbvio de uma cronologia de especificações técnicas dos equipamentos e costuma ser pautada por comparações centradas no custo-benefício, em que o gasto agregado da realização em película é comparado com a maior agilidade no set de câmeras digitais, o que resulta em menos

${ }^{12} \mathrm{O}$ uso de ferramentas digitais é amplamente recomendado em manuais ou guias de produção dedicado a realizadores como Clark e Spohr (2002), Clevé (1999), Honthaner (2001) pelos mesmos motivos: menores custos e maior agilidade, o que abriria mais espaço para filmes que corressem mais riscos criativos, uma ideia legitimada perante o senso comum a partir de movimentos como o Dogma 95. despesas e uma maior viabilidade de execução dos filmes ${ }^{12}$. Frente às afirmativas do custo-benefício que estão alinhadas com as ideias de razão tecnológica de Marcuse (1998), ater-se à película fora do cinema de grande orçamento revela-se apenas uma afirmação de resistência de nicho alinhada à cultura retrô mapeada por Guffey (2006).

A maioria dos projetos de crowdfunding citados no segmento anterior deste texto viabilizam-se também por conta desta relação positiva de custo-benefício, favorável ao pequeno realizador. O questionamento neste caso se deslocaria: quais marcas esta imagem financiada coletivamente e digital traz? Para qual cotidiano é aberta essa janela? Em uma observação preliminar é possível afirmar que projetos de documentário predominam no cenário brasileiro, um movimento que destaca o valor cultural presente fora da ideia de produção ficcional tradicional em estúdio. 
${ }^{13}$ Entendemos como convencional aqui a mescla de imagens ontologicamente distintas (captadas com câmera e elenco, ilustrações, animações, etc.) que busca se passar desapercebida, o discurso fundamental dos efeitos visuais. Além desta convenção está a mescla onde é possível perceber as emendas e as diferenças entre os elementos reunidos na imagem.

\footnotetext{
${ }^{14}$ Disponível em <http://youtubebrblog. blogspot.com.br/2012/05/o-youtubeesta-fazendo-7-anos-e-voces.html>. Acesso em 05 Jul. 2013.
}

Uma segunda linha do diálogo entre cinema e digitalidade a aponta como um facilitador da manipulação da imagem para processamento com caráter expressivo, estético ou de efeitos visuais. Embora esta linha se sobreponha à primeira no caráter de substituição, traz algo essencialmente novo: considerar o digital como capaz de potenciar a pós-produção para além do que fora formulado com as reflexões sobre a montagem de Eisenstein (2002) que fundamentam a compreensão sobre o tema na área. Nesta linha, a pós-produção pode ser entendida como algo criativo não apenas no tensionamento provocado pelo choque ou pela continuidade entre os planos e em sua relação com a trilha musical - como afirmava o pensamento tradicional da montagem -, mas também como uma prática criadora interna ao quadro capaz de borrar os limites ontológicos dados pela origem das imagens em que a captação com câmeras seja mesclada com elementos gráficos e animações de maneiras não convencionais ${ }^{13}$.

Um exemplo desta apropriação digital que expande um repertório de linguagem audiovisual pode ser observado no renovado uso de split screen (tela dividida) como uma forma de diagramação expressiva, como em The Tracey Fragments (McDonald, 2007), em que a perturbação mental da protagonista é proporcional ao número de janelas irregulares abertas na tela - tentando dar conta de um mundo complexo e contraditório onde apenas uma imagem única não mais o representa. Outro exemplo são as vinhetas internas ao filme OSS 117 - Rio Ne Répond Plus (Hazanavicius, 2009) em que o fracionamento da tela em dezenas de pequenas janelas seria inviável com ferramentas pré-digitais, por conta da deterioração da imagem que o processo traria.

Uma crítica às duas primeiras linhas é que elas podem operar apenas como uma aceleração dos processos já constituídos previamente no cinema. Câmeras que permitem fazer filmes mais rapidamente e com menos riscos financeiros para seus produtores estão presentes desde a difusão da bitola de $16 \mathrm{~mm}$, a partir de sua apropriação por cinejornalismo na década de 1930. Uma manipulação mais intensa das imagens em pós-produção permitiria uma tradução mais fiel do imaginário dos realizadores para as telas, mas é difícil afirmar que os pioneiros dos efeitos visuais como Georges Méliès não tivessem alcançado este objetivo no início do século XX. É fácil perder de vista a capacidade de disrupção dos processos que é trazida pela digitalidade e apenas se conformar com sua dinamização.

A disrupção das práticas anteriores surge em uma terceira linha, caracterizada pela ubiquidade de câmeras digitais nas mãos de incontáveis indivíduos que as apontam para seu cotidiano de forma pouco sistematizada e em grande parte por fora das convenções de bem fazer cinematográfico, um movimento explorado entre outros por Tietzmann e Rossini (2012). Marcados pela brevidade e pela denotação de uma experiência a partir do registro da imagem, vídeos publicados online têm surgido em abundância e desafiado as classificações de gênero e de gosto previamente estabelecidas, um problema de análise expressado em uma postagem no blog brasileiro do YouTube:

Hoje 72 horas de vídeo são subidas no site por minuto. Como tantas crianças de 7 anos ao redor do mundo, nós estamos crescendo tão rápido! Em outras palavras, a cada minuto vocês agora fazem o upload do equivalente a três dias inteiros em vídeo, em vez de dois (YOUTUBE, 2012) ${ }^{14}$.

Este movimento guarda contornos de multidão, dialoga com os fatores elencados por Braet e Spek (2010) e está à margem do cinema como o conhecemos, embora em muitos sentidos seu conteúdo releia as convenções dos primeiros anos do meio em que o registro do cotidiano e a busca em espaços privados por algo que possa receber atenção pública mobiliza os realizadores improvisados de maneira desapegada de um domínio da representação ou da busca de uma qualidade técnica da imagem. 
${ }^{15}$ Disponível em: <http:// www.youtube.com/watch?v= OBlgSz8sSM\&feature=youtu.be>. Acesso em: 05 Jul. 2013.
${ }^{16}$ Cópias não autorizadas foram responsáveis indiretas pela preservação de versões de filmes como Viagem à Lua (do original Voyage Dans La Lune), filme de 1902 de Georges Méliès, quando companhias concorrentes duplicavam sem licença as cópias (DECHERNEY, 2012). O catálogo dos mais de 500 filmes de Méliès só foi sendo preenchido à medida que seus filmes, que haviam sido pirateados, foram encontrados.
É possível identificar uma linha de continuidade entre a Saída da fábrica ou o Desjejum do bebê dos irmãos Lumière com tais vídeos postados online. Tanto em Lyon nos finais do século XIX quanto online hoje há uma ideia de preparar-se para ser filmado. Vídeos familiares com mais de 530 milhões de visualizações desde 2007 como Charlie bit my finger - again! $!^{15}$ - no qual os irmãos ingleses Charlie e Harry estão sentados e durante um plano sem cortes o bebê morde o dedo do irmão mais velho - sublinham a face do audiovisual feito pela multidão: emana do cotidiano, redescobrindo uma ideia de realismo da imagem na simplicidade da captação. Embora tais vídeos de bebês, cães e gatos não sejam idênticos ao cinema narrativo quanto à sua constituição, são contaminados por ele nas transformações dos códigos de representação do que seria realidade nas telas.

O volume de material em vídeo produzido, postado e circulado online também destaca a ubiquidade de computadores pessoais, de dispositivos móveis e de conexão em rede, nos quais a linha que separa produtor de consumidor é borrada, o que favorece a esta multidão tanto fazer circular uma produção quanto consumir conteúdos alheios, tema do próximo segmento deste texto.

\section{Circulação do cinema para além dos meios tradicionais}

Inseridas em um panorama pré-existente em que filmes já eram entregues aos seus espectadores por diversos meios como o cinema em sala, a televisão aberta, por assinatura e o vídeo doméstico, as tecnologias digitais ampliaram o acesso à produção cinematográfica. Segundo Barone (2008: 06), essas tecnologias "estão possibilitando a ampliação da circulação, inclusive comercial, do produto cinematográfico em outros suportes". Em paralelo aos canais oficiais também tem se tornado evidente com a digitalidade a presença da pirataria, a apropriação não autorizada de produtos ou serviços que estejam sob resguardo de direitos autorais. No contexto cinematográfico, é definida por Segrave (2003) como o uso ou a reprodução e distribuição não autorizada de um filme.

No panorama de distribuição e exibição anterior às tecnologias digitais, consolidara-se uma hierarquia de janelas de exibição, usualmente reservando a estreia para as salas de cinema e o final do processo nas reprises da televisão aberta e no vídeo doméstico. Este trajeto era análogo à resolução de imagem oferecida em cada meio, sendo a exibição em sala com uma película $35 \mathrm{~mm}$ o standard profissional entendido como referência do meio, enquanto a entrega doméstica era considerada sua versão mais pobre. Depois da consolidação da indústria cinematográfica nas primeiras décadas do século $X X^{16}$, a circulação de cópias piratas de filmes foi reduzida significativamente.

As cópias não autorizadas tornaram-se uma questão presente a partir da consolidação do vídeo doméstico com a bitola VHS, primeiro suporte de vídeo usado para a revenda de filmes a partir de 1977, segundo Wasser (2001). A possibilidade de gravar programas da televisão e de duplicar filmes pré-gravados semeou a noção de que estas cópias não seriam pirataria - uma palavra investida de conotações negativas e jurídicas -, mas uma possibilidade de diálogo e trocas não-comerciais entre indivíduos, grupos e fãs. Essencialmente, essas práticas de duplicação analógica poderiam ser entendidas como um direito de uso, um movimento encarado como perda de receitas pelas empresas do ramo. Esse debate só aumentou com a difusão dos computadores pessoais na década de 1980 que, a partir da década seguinte, passaram a ter sua capacidade de armazenamento e de processamento de conteúdos multimídia constantemente melhorados. Para completar o cenário, a penetração de internet em banda larga, ao longo da primeira década do século XXI, criou condições para a aceitação de plataformas de vídeo online.

Atualmente, no Brasil são mais de 80 milhões de internautas (AGUIARI, 2012), um número que cresceu $1.484,9 \%$ de 2000 a 2011 (INTERNET WORLD STATS, 
${ }^{17}$ Em 2009, o YouTube anunciou que começaria a exibir filmes e programas de televisão, disponibilizados pelas próprias emissoras e produtoras (YouTube Official Blog, 2009).

${ }^{18}$ Disponível em <http://www. opensubtitles.org>. Acesso em $08 \mathrm{Jul}$. 2013.
2012). Estes usuários, conforme Aguiari (2012), em sua maioria (45\%) tem acesso à rede em velocidades que variam de $512 \mathrm{Kbps}$ a $2 \mathrm{Mbps}$, seguidos por 2 a $8 \mathrm{Mbps}$ (27\% dos usuários), um limiar de velocidade que pode não oferecer a experiência para consumo de vídeo online que tornaria esses usuários capazes de substituir a televisão por completo, mas que dá a eles acesso a um vasto universo de produtos audiovisuais online. Esses dados nos mostram que a circulação de material por meios paralelos, mesmo que não substitua completamente a circulação por meios tradicionais, levanta a possibilidade de muitas pessoas terem acesso às obras.

A internet possibilitou o aumento desse leque de exibição oficial, como canais de aluguel de filme, tais como Blockbuster, Netflix, Sunday TV, Globo TV+, e canais de exibição de vídeos, como o Vimeo e o YouTube ${ }^{17}$. A internet possibilitou também o aumento das vendas diretas de mídia física, através da possibilidade do e-commerce.

Além desses canais, que complementam a comercialização dos filmes, existem também muitos outros que ampliam a circulação dessas obras, todavia, de forma não oficial. Dentre estes, podemos citar a venda de videocassete, DVD e Blu-Ray piratas, download através de sites de torrent, sites de download direto ou blogs que fazem curadoria desses conteúdos e sites de visualização de vídeos. A subversão do digital constrói-se justamente em suas capacidades de ser um grande meio de armazenamento, tradução, transmissão e transformação de praticamente qualquer informação passível de ser registrada. De acordo com Lessig (2008) e Castells (2003), a internet foi desenvolvida através de uma estrutura aberta e de livre acesso, estimulando a colaboração entre os usuários e interpretando qualquer tipo de censura como obstáculo técnico.

Tomamos como exemplo de circulação que foi estendida através da digitalidade o filme The Croods (2013), dos diretores Kirk de Micco e Chris Sanders. O filme foi escolhido por estar entre os que tiveram mais legendas baixadas no site Open Subtitles ${ }^{18}$. A animação foi produzida pela DreamWorks Animation e, segundo o Internet Movie Database - IMDB (2013), chegou aos cinemas americanos em 22 de março de 2013. Durante a sua primeira semana de exibição, o filme esteve em 4.046 salas de cinema dos Estados Unidos. Já na última semana cadastrada no site IMDB - de 30 de junho a 06 de julho do decorrente ano -o filme esteve em 307 salas no mesmo país, diminuindo consideravelmente o número de espectadores.

O fato de estar sendo exibido em menos salas dificulta o acesso das pessoas ao filme, o que consequentemente, leva a uma grande diminuição do número de espectadores. Em contrapartida, o filme tem a possibilidade de continuar em circulação por tempo indeterminado através dos canais de circulação citados anteriormente.

Em uma busca pelo filme através dos canais não-oficiais de distribuição na internet, encontramos vários resultados. No site Torrentz.eu, obtivemos 118 resultados para o filme, sendo que o primeiro foi publicado há três meses, ou seja, bem próximo ao lançamento do filme nos cinemas. Já no site The Pirate Bay encontramos 89 resultados, sendo o primeiro publicado em 23 de março de 2013, apenas um dia depois do seu lançamento nos cinemas. Essas datas e o grande número de resultados é um grande indício de que o filme foi bastante exibido nas primeiras semanas do lançamento e nos mostra que a obra tem muitas chances de continuar em circulação através da internet mesmo depois de sair dos cinemas.

\section{Considerações finais}

Os autores deste texto entendem que ainda não há uma compreensão ampla das marcas da digitalidade em todo o escopo da realização audiovisual específica ao cinema. Elas seguramente são mais profundas e multifacetadas do que esta breve reflexão consegue dar conta. De maneira geral, há marcas da digitalidade 
na aceleração e qualificação de processos pela substituição de equipamentos. Essas mudanças em si não provocam transformações automáticas nos conteúdos, uma vez que é possível acoplar tecnologias digitais a rotinas já estabelecidas. Assim, defendemos que a mudança não está dada a partir da tecnologia, mas vem da apropriação criativa feita pelos usuários ao negociarem possibilidades percebidas que ainda não foram sistematizadas em convenções de gosto e estilo e que frequentemente são pautadas por relações que se situam à margem do comércio.

Autores como Negroponte (1995) e Lessig (2008) questionam os modelos tradicionais de produção e de distribuição ao afirmarem que a possibilidade de replicação sem perda qualidade a cada geração de cópia corrói o monopólio das estruturas de distribuição previamente estabelecidas. Novos modelos de negócios se adaptam a este panorama, como os serviços de streaming de vídeo cujo maior representante é o Netflix. Em contrapartida, o aumento do número de canais e de oportunidades para consumir conteúdo audiovisual coloca em xeque os modelos tradicionais de financiamento e de escolha de prioridades por parte das empresas, um vácuo que tende a ser atendido pela pirataria e pela multidão de realizadores improvisados ou em estágios iniciais de profissionalização que ocupam os espaços online e desequilibram noções de gosto e questionam a ideia da narrativa como a grande força de atração do audiovisual.

Enfim, o cinema ainda guarda residualmente uma lembrança das práticas e tecnologias que Ihe deram forma. Mais do que o cotidiano da realização e pesquisa sobre a área tais memórias se tornaram também imateriais, operando como uma identidade da área em contínua transformação.

\section{Referências Bibliográficas}

BARONE, João Guilherme. Exibição, crise de público e outras questões do cinema brasileiro. Porto Alegre: Sessões do Imaginário, 2008.

BLOCK, Alexis Ben; WILSON, Lucy Aubrey. George Lucas's Blockbusting: A Decadeby-Decade Survey of Timeless Movies Including Untold Secrets of Their Financial and Cultural Success. New York: It Books, 2010.

BENKLER, Yochai. The wealth of networks: how social production transforms markets and freedom. New Haven and London: Yale University Press, 2006.

BRAET, Olivier; SPEK, Sander. Crowdfunding the Movies: A Business Analysis to Support Moviemaking in Small Markets. Proceedings of the 8th international interactive conference on Interactive TV \& Video. New York: ACM, 221-228. 2010

CASTELLS, Manuel. Internet e sociedade em rede. In: MORAES, Dênis de (Org.). Por uma outra comunicação. Record: Rio de Janeiro, 2003.

CLARK, Barbara ; SPOHR, Susan J. Guide to Postproduction for TV and Film: Managing the Process. Burlington: Focal Press, 2002.

CLEVÉ, Bastian. Film Production Management. Boston: Focal Press, 1999.

DECHERNEY, Peter. Hollywood's Copyright Wars. New York: Columbia University Press, 2012.

EISENSTEIN, Sergei M. A forma do filme. Rio de Janeiro: Jorge Zahar, 2002.

FELINTO, Erick. Crowdfunding: entre as multidões e as corporações. Revista Comunicação, Mídia e Consumo. Ano 9. Vol. 9 n. 26. ESPM. São Paulo. P. 137-150. Nov. 2012. 
GASKELL, Ed. The Complete Guide to Digital Video. London: Cengage Learning, 2003.

GUFFEY, Elizabeth E. Retro: The Culture of Revival. Londres: Reaktion Books, 2006.

HONTHANER, Eve Light. The Complete Film Production Handbook. Boston: Focal Press, 2001.

JENKINS, Henry. Cultura da Convergência. São Paulo: Aleph, 2009.

LESSIG, Lawrence. Remix: Making Art and Commerce Thrive in the Hybrid Economy. New York: The Penguin Press, 2008.

LÉVY, Pierre. A Inteligência Coletiva: por uma antropologia do ciberespaço. São Paulo: Loyola, 1998.

MANNONI, Laurent. A Grande Arte da Luz e da Sombra. São Paulo: Editora Senac \& Editora UNESP, 2003.

MARCUSE, Herbert. Some Social Implications of Modern Technology. In: Collected Papers of Herbert Marcuse: Technology, War and Fascism, Volume 1. Londres: Routledge, 1998.

NEGROPONTE, Nicholas. A vida digital. São Paulo: Companhia das Letras, 1995.

OWENS, Jim. Television Sports Production. Nova Iorque: Focal Press, 2007.

SANTAELLA, Lucia. Linguagens líquidas na era da mobilidade. São Paulo: Paulus, 2007.

SEGRAVE, Kerry. Piracy in the Motion Picture Industry. North Carolina: McFarland, 2003.

SELONK, Aletéia Patrícia de Almeida. Distribuição Cinematográfica no Brasil e suas Repercussões Políticas e Sociais - um estudo comparado da distribuição cinematográfica nacional e estrangeira. Dissertação (Mestrado em Comunicação Social) - Faculdade de Comunicação Social, Pontifícia Universidade Católica do Rio Grande do Sul, Porto Alegre, 2004.

SORENSEN, Inge. Crowdsourcing and outsourcing: the impact of online funding and distribution on the documentary film industry in the UK. Media, Culture \& Society, v..34, n.6. P. 726-743. 2012.

SUROWIECKI, James. A sabedoria das multidões. Rio de Janeiro: Record, 2006.

TIETZMANN, Roberto; ROSSINI, Miriam de Souza. De Volta Para o Passado: o audiovisual de acontecimento contemporâneo. In: BENEVENUTO, Álvaro; STEFFEN, César (Orgs.). Tecnologia, pra quê? Os Impactos dos Dispositivos Tecnológicos no Campo da Comunicação. Porto Alegre: Armazém Digital, 2012.

WASSER, Frederick. Veni, Vidi, Video: The Hollywood Empire and the VCR. Austin: Texas film and media studies series, 2001.

YOUNGBLOOD, Gene. Expanded Cinema. Nova lorque: P. Dutton \& Co. Inc., 1970.

\section{Referências eletrônicas}

AGUIARI, Vinicius. PNBL e $3 G$ fazem número de brasileiros online chegar a 79,9 milhões. In: Revista Info. Disponível em: <http://info.abril.com.br/noticias/internet/ brasil-fecha-2011-com-79-9-mi-de-internautas-10042012-29.shl>. Acesso em: 11 Jul. 2013.

CATARSE. Disponível em: <www.catarse.me>. Acesso em: 09 Jul. 2013. 
IMDB. Internet Movie Data Base. Disponível em <http://www.imdb.com/>. Acesso em: 08 Jul. 2013.

INOCENTE. Disponível em <http://inocentedoc.com/>. Acesso em: 26 Mai. 2013.

INTERNET World Stats. Internet Users in South America. Miniwatts Marketing Group, 2012. Disponivel em <http://www.internetworldstats.com/stats15.htm>. Acesso em: 11 Jul. 2013.

KICKSTARTER. Disponível em <www.kickastarter.com>. Acesso em: 07 Jul. 2013

OPEN Subtitles. Disponível em <http://www.opensubtitles.org/>. Acesso em: 08 Jul. 2013.

THE PIRATE Bay. Disponível em <http://thepiratebay.org/>. Acesso em: 08 Jul. 2013.

Torrentz.eu. Disponível em <http://torrentz.eu/>. Acesso em: 08 Jul. 2013.

YOUTUBE. Disponível em <http://www.youtube.com/>. Acesso em: 08 Jul. 2013.

YOUTUBE Official Blog. Watch Shows and Movies on YouTube. Disponível em <http:// youtube-global.blogspot.com.br/2009/04/watch-shows-and-movies-on-youtube. html>. Acesso em: 11 Jul. 2013.

\section{Filmes citados}

BELO MONTE: Anúncio de uma guerra. Direção: André D'Elia. Produção: André D'Elia, Bia Vilela. Intérprete: Raoni. Brasil: Cinedelia, 2012.

GUERRA nas Estrelas (Star Wars). Direção: George Lucas. Produção: Gary Kurtz, George Lucas. Roteiro: George Lucas. Intérpretes: Mark Hamill, Harrison Ford, Carrie Fisher. EUA: Lucasfilm, 1977.

IRON SKY (Deu a Louca nos Nazis). Direção: Timo Vuorensola. Roteiro: Johanna Sinisalo, Jarmo Puskala, Michael Kalesniko, Timo Vuorensola. Intérpretes: Julia Dietze, Christopher Kirby, Götz Otto. USA: Blind Spot Pictures Oy, 27 Films Production, Nwe Holland Pictures, Tuotantoyhtiö Energia, Yleisradio (YLE), 2012.

OS CROODS (The Croods). Direção: Kirk De Micco e Chris Sanders. Produção: Kristine Belson e Jane Hartwell. Roteiro: John Cleese, Chris Sanders e Kirk De Micco. Intérpretes: Nicolas Cage, Emma Stone, Ryan Reynolds. EUA: DreamWorks Animation, 2013.

OSS 117 - Rio não responde mais (OSS 117 - Rio ne répond plus). Direção: Michel Hazanavicius. Produção: Eric Altmayer, Nicolas Altmayer. Roteiro: Jean Bruce, JeanFrançois Halin, Michel Hazanavicius. Intérpretes: Jean Dujardin, Louise Monot, Rüdiger Vögler. França: Mandarin Films, 2009.

VIAGEM À LUA (Voyage Dans La Lune). Direção: Georges Méliès. Produção: Georges Méliès. Roteiro: Jules Verne, Georges Méliès, H. G. Wells. Intérpretes: Victor André, Bleuette Bernon, Brunnet. França: Star-Film, 1902.

THE TRACEY FRAGMENTS. Direção: Bruce McDonald. Produção: Paul Barkin, Phyllis Laing, Sarah Timmins. Roteiro: Maureen Medved. Intérpretes: Ellen Page, Max McCabe-Lokos. EUA: Téléfilm Canada, Shadow Shows, 2007.

WESTWORLD - Onde ninguém tem alma (Westworld). Direção: Michael Crichton. Produção: Paul N. Lazarus III. Roteiro: Michael Crichton. Intérpretes: Yul Brynner, James Brolin. EUA: MGM, 1976. 